\title{
Laparoscopic cystectomy for pancreatic echinococcosis: A case report and literature review
}

\author{
Ashraf Imam ${ }^{1, *}$, Tawfik Khoury, ${ }^{2, *}$, Dani Weis ${ }^{3}$, Harbi Khalayleh ${ }^{1}$, \\ Muhammad Adeleh ${ }^{3}$, and Abed Khalaileh ${ }^{3}$
}

${ }^{1}$ Department of Surgery, Kaplan Medical Center, Rehovot, Departments of ${ }^{2}$ Gastroenterology and Liver Diseases and ${ }^{3}$ Surgery, Hadassah Medical Center, Jerusalem, Israel

\begin{abstract}
Cystic echinococcosis (CE) is a widely endemic helminthic disease caused by infection with the Echinococcus granulosus tapeworm. Following ingestion of eggs, hydatid cysts develop, most frequently in the liver and lungs, but occasionally in other organs. Infection of the pancreas by hydatid cysts is very rare, even in endemic areas. Most cases of pancreatic hydatid cysts reported in the literature were treated surgically using traditional open laparotomy. There are only few case reports describing laparoscopic treatment for this disease. Herein, we report on an eighteen-year-old female patient who was referred to our institution with a hydated pancreatic tail cyst. After a course of treatment with Albendazole, we successfully performed laparoscopic splenic-sparing distal pancreatectomy to remove the cyst with an uneventful intra- and post-operative course. (Ann Hepatobiliary Pancreat Surg 2019;23:87-90)
\end{abstract}

Key Words: Hydatid cyst; Pancreas; Laparoscopic cystectomy

\section{INTRODUCTION}

Hydatid cystic disease is caused by infection with the Echinococcus tapeworms, part of the Taeniidae family. Four species of Echinococcus are known to cause infections in humans. Of these, Echinococcus granulosus and E. alveolaris are the most common, causing cystic and alveolar echinococcosis, respectively. Primary carriers are dogs, foxes and wolves, which are infected by consumption of offal from infected intermediate hosts, such as sheep or pigs.

Once in the small intestine of the primary carriers, the parasites remain firmly attached to the mucosa, later shedding gravid proglottids that are excreted within the carrier's feces. Within each proglottid, there are hundreds of eggs which can then be ingested by intermediate hosts. ${ }^{1}$ Humans, who are accidental hosts and do not play a role in the biological cycle, are infected by ingesting ova from soil or water contaminated by the feces of dogs. ${ }^{2}$ In humans the infection begins with an incubation period dur- ing which there is a release of oncospheres from the eggs. These are able to penetrate the human intestinal wall and enter the portal venous system, allowing them to gain access to the liver, lungs and other organs ${ }^{3}$ where they can begin cyst development. ${ }^{4,5}$

Echinococcal cysts are most commonly found in liver (70\%) and lung (20\%) tissue. However, $10 \%$ of cysts can be found elsewhere in the body, including the spleen $(6 \%)$, heart $(2 \%)$, kidney $(2 \%)$, and brain $(<2 \%){ }^{3}$ Pancreatic hydatid cyst infection is very rare even in endemic areas. ${ }^{6}$ Surgery, open or laparoscopic; conservative or radical, is still the treatment of choice for hydatid disease in all locations. ${ }^{7}$

Herein, we present a case of hydatid cyst in the distal pancreas which was treated with laparoscopic resection because of its outstanding rarity and diagnostic challenge considering other possible causes of pancreatic cysts.

Received: July 10, 2018; Revised: July 21, 2018; Accepted: July 26, 2018

Corresponding author: Abed Khalaileh

Department of Surgery, Hadassah Medical Center, Hebrew University, Ein-Kerem, Jerusalem, POB 1200, IL91120, Israel

Tel: +972-508573917, Fax: +972-49870180, E-mail: Hbedk@hadassah.org.il

*Ashraf Imam and Tawfik Khoury contributed equally to this work.

Copyright (C) 2019 by The Korean Association of Hepato-Biliary-Pancreatic Surgery

This is an Open Access article distributed under the terms of the Creative Commons Attribution Non-Commercial License (http://creativecommons.org/ licenses/by-nc/4.0) which permits unrestricted non-commercial use, distribution, and reproduction in any medium, provided the original work is properly cited. Annals of Hepato-Biliary-Pancreatic Surgery • pISSN: 2508-5778 - eISSN: 2508-5859 


\section{CASE}

An 18-year-old woman was referred to our hepatobiliary unit for consultation following diagnosis of an enlarging cyst in the tail of the pancreas.

The patient had undergone a partial left lung resection four years earlier as treatment for a left pulmonary echinococcal cyst. During that time, a $3.5-\mathrm{cm}$ cyst was found in the tail of the pancreas on computed tomography (CT) scan (Fig. 1). It was then decided to monitor the pancreatic cyst. Four years later, a routine CT scan was performed; it showed enlargement of the cyst to $4 \mathrm{~cm}$ and thickening of the cyst walls. A complete workup, including serology for echinococcus, was performed, yielding positive results. It should be emphasized that the patient was completely asymptomatic during the follow-up period until the three months prior to the abdominal surgery, when she started complaining of vague abdominal pain.

A course of treatment with albendazole $400 \mathrm{mg}$ twice daily and Praziqunantel $20 \mathrm{mg} / \mathrm{kg}$ three times daily was given preoperatively for one month, and then a laparoscopic spleen-sparing distal pancreatectomy was performed. The resected tissues were pathologically examined, and the diagnosis of echinococcal cyst with surrounding normal tissue was confirmed.

The postoperative course was eventless, and the patient was discharged on the fifth postoperative day with continued oral albendazole therapy of $400 \mathrm{mg}$ twice daily for another two months. The patient was followed up for four years with unremarkable clinical course.

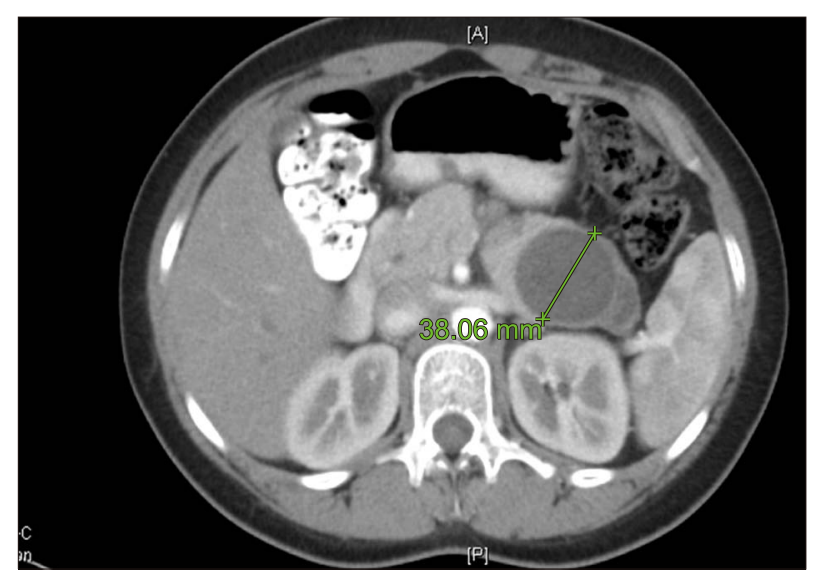

Fig. 1. Computed tomography demonstrating hydated cyst in the pancreatic tail.

\section{DISCUSSION}

Hydatid cysts can be most frequently found in the liver, since it is the first and the largest filter of parasitic embryos migrating from the intestine via the portal system. If they escape the hepatic filter, the embryos enter the systemic circulation and settle in the lungs or, rarely, in other organs. ${ }^{8}$ Extra-hepatic primary hydatid disease is rarely found without hepatic involvement. ${ }^{9}$ The embryos of hydatid cysts that end up in the pancreas do so mainly by the hematologic route or by peripancreatic lymphatic invasion, and, in very rare cases by retroperitoneal spread. ${ }^{10}$

Involvement of the pancreas in hydatid cyst disease is very rare, even in endemic areas. ${ }^{6}$ Within the pancreas, the head is more frequently involved (57\%), followed by the body $(24 \%)$ and the tail $(19 \%)^{7}$

The cysts can cause nonspecific symptoms, commonly related to the location and size of the cyst, but they are usually asymptomatic. For large cysts, the most commonly found symptom is abdominal pain. ${ }^{11}$

Hydatid cysts presenting in the head of the pancreas can cause obstructive jaundice and pancreatitis, ${ }^{12}$ whereas cysts that present in the body or tail usually remain asymptomatic until they grow large enough to compress adjacent organs or anatomical structures. ${ }^{11}$ The diagnosis of hydatid cyst is made mainly via an Enzyme-linked Immunosorbent Assay (ELISA) test for echinococcal antigens. ${ }^{7}$ Ultrasound is considered the most sensitive tool for detecting cystic structures, including floating membranes, hydatid sand, and floating daughter cysts. The water-lily sign, water attenuation, and calcifications detected by CT scanning are also highly suggestive of hydatid cyst. $^{13}$ Despite the aforementioned diagnostic modalities, definitive diagnosis of hydatid disease of the pancreas is made mainly during surgery. ${ }^{7}$

The treatment of hydatid cysts is mainly surgical. However, a pre- and post-operative course of albendazole and praziquantel can help in sterilizing the cyst, thus decreasing the chance of an anaphylactic reaction because of cyst rupture and reducing the recurrence rate postoperatively. ${ }^{14}$ The surgical approach depends on cyst location and size and on whether there is communication between the cyst and the pancreatic or common bile ducts. Pancreatic head cysts with no duct communication can be managed by cystectomy with external drainage. omento- 
Table 1. studies reported laparoscopic treatment for pancreatic hydated cyst

\begin{tabular}{|c|c|c|c|c|c|c|c|c|}
\hline References & Year & $\begin{array}{l}\text { Age } \\
\text { (years) }\end{array}$ & Gender & $\begin{array}{c}\text { Cyst } \\
\text { location }\end{array}$ & $\begin{array}{l}\text { Cyst size } \\
(\mathrm{mm})\end{array}$ & Operation & Conversion & Complication \\
\hline Agrawal et al. & 2011 & 5 & $\mathrm{~F}$ & Head & $120 * 100$ & $\begin{array}{l}\text { Enucleation cholangiography } \\
\text { cholecystectomy }\end{array}$ & $\begin{array}{l}\text { Converted to } \\
\text { open }\end{array}$ & No \\
\hline Suryawanshi et al. & 2011 & 20 & M & Head & $80 * 80$ & Cyst evacuation and omentoplasty & No conversion & No \\
\hline Boubbou et al. & 2010 & 38 & M & Head & Not specified & PAIR drainage cystogastrostomy & No conversion & No \\
\hline
\end{tabular}

pexy with pericystectomy, or even by a whipple procedure. If a cyst communicates with the pancreatic duct, it can be treated by fashioning a cysto-jejunal, cysto-duodenal, or cysto-gastric anastomosis. Bedioui et al. ${ }^{15}$ advocate doing intraoperative cholangiopancreatography to identify fistulae between the cyst and the main pancreatic duct, thus leading to the most appropriate surgical approach.

For cysts located in the pancreatic body or tail, the most appropriate approach is a spleen-preserving distal pancreatectomy, ${ }^{16}$ as was performed in our case. Khoury et al. ${ }^{17}$ concluded that the laparoscopic approach to uncomplicated hydatid cysts of the liver was a safe, effective option with favorable long-term results.

Although there are many articles about laparoscopic excision of hydatid cysts in other organs, there are only a few case reports describing this approach in pancreatic disease with overall satisfactory results and no complications being reported (Table 1). Agrawal and Parag ${ }^{18}$ described a five-year-old female patient who was initially diagnosed with a choledochal cyst and who was taken for a laparoscopic cyst excision. On laparoscopy, the cystic lesion was found to originate from the pancreatic head. An aspirated fluid sample from the cyst turned up clear. This finding indicated the presence of a hydatid cyst, and after conversion to laparotomy, cyst enucleation was performed. Another report by Suryawanshi et al. ${ }^{19}$ described a 20- year-old male patient with hydatid cyst of the head of the pancreas that was diagnosed preoperatively. An uneventful laparoscopic cyst evacuation and omentoplasty was performed. Recently, Boubbou et al. ${ }^{20}$ described a 38-year- old man who presented with jaundice, abdominal pain, and an epigastric mass that was diagnosed preoperatively as a hydatid cyst. The patient was treated using a minimally invasive approach in which drainage and cystgastrostomy was performed laparoscopically.

Pancreatic hydatid cyst is extremely rare. The main thera- peutic option is still open surgical laparotomy. However, we believe that a minimally invasive approach is appropriate for the treatment of pancreatic hydatid cyst if a full and accurate preoperative workup and diagnosis is made, and the operating surgeon is experienced in laparoscopic technique.

\section{REFERENCES}

1. Siracusano A, Teggi A, Ortona E. Human cystic echinococcosis: old problems and new perspectives. Interdiscip Perspect Infect Dis 2009;2009:474368.

2. Yagmur Y, Akbulut S. Unusual location of hydatid cysts: a case report and literature review. Int Surg 2012;97:23-26.

3. Pakala T, Molina M, Wu GY. Hepatic echinococcal cysts: a review. J Clin Transl Hepatol 2016;4:39-46.

4. Lewall DB. Hydatid disease: biology, pathology, imaging and classification. Clin Radiol 1998;53:863-874.

5. Pedrosa I, Saíz A, Arrazola J, Ferreirós J, Pedrosa CS. Hydatid disease: radiologic and pathologic features and complications. Radiographics 2000;20:795-817.

6. Jai SR, El Hattabi K, Bensardi F, Chehab F, Khaiz D, Bouzidi A. Primary hydatid cyst of the pancreas causing obstructive jaundice. Saudi J Gastroenterol 2007;13:191-193.

7. Dziri C, Haouet K, Fingerhut A. Treatment of hydatid cyst of the liver: where is the evidence? World J Surg 2004;28:731-736.

8. Balik AA, Celebi F, Başglu M, Oren D, Yildirgan I, Atamanalp SS. Intra-abdominal extrahepatic echinococcosis. Surg Today 2001;31:881-884.

9. Hamamci EO, Besim H, Korkmaz A. Unusual locations of hydatid disease and surgical approach. ANZ J Surg 2004;74:356-360.

10. Ismail K, Haluk GI, Necati O. Surgical treatment of hydatid cysts of the pancreas. Int Surg 1991;76:185-188.

11. Akbulut S, Yavuz R, Sogutcu N, Kaya B, Hatipoglu S, Senol A, et al. Hydatid cyst of the pancreas: report of an undiagnosed case of pancreatic hydatid cyst and brief literature review. World J Gastrointest Surg 2014;6:190-200.

12. Safioleas MC, Moulakakis KG, Manti C, Kostakis A. Clinical considerations of primary hydatid disease of the pancreas. Pancreatology 2005;5:457-461.

13. Masoodi MI, Nabi G, Kumar R, Lone MA, Khan BA, Naseer Al Sayari K. Hydatid cyst of the pancreas: a case report and brief review. Turk J Gastroenterol 2011;22:430-432.

14. Cobo F, Yarnoz C, Sesma B, Fraile P, Aizcorbe M, Trujillo R, et al. Albendazole plus praziquantel versus albendazole alone as a pre-operative treatment in intra-abdominal hydatisosis caused by Echinococcus granulosus. Trop Med Int Health 1998;3: 462-466.

15. Bedioui H, Chebbi F, Ayadi S, Daghfous A, Bakhtri M, Jouini 
M, et al. [Primary hydatid cyst of the pancreas: diagnosis and surgical procedures. Report of three cases]. Gastroenterol Clin Biol 2008;32:102-106. French.

16. Trigui A, Rejab H, Guirat A, Mizouni A, Ben Amar M, Mzali $\mathrm{R}$, et al. Hydatid cyst of the pancreas. About 12 cases. Ann Ital Chir 2013;84:165-170.

17. Khoury G, Abiad F, Geagea T, Nabout G, Jabbour S. Laparoscopic treatment of hydatid cysts of the liver and spleen. Surg Endosc
2000;14:243-245

18. Agrawal S, Parag P. Hydatid cyst of head of pancreas mimicking choledochal cyst. BMJ Case Rep 2011;2011. pii:bcr0420114087.

19. Suryawanshi P, Khan AQ, Jatal S. Primary hydatid cyst of pancreas with acute pancreatitis. Int J Surg Case Rep 2011;2:122-124.

20. Boubbou M, Boujraf S, Sqalli NH, Maaroufi M, Tizniti S. Large pancreatic hydatid cyst presenting with obstructive jaundice. Arab J Gastroenterol 2010;11:47-49. 